\title{
VER Y NO PUBLICAR, PUBLICAR SIN CONOCER: HISTORIAS SOBRE LA REPRESENTACIÓN DEL RÍO MADEIRA
}

\author{
Maria de Fatima Costa \\ Universidade Federal de Mato Grosso
}

\begin{abstract}
El autor del artículo debería saber que sólo los hechos publicados se tienen como adquiridos por la ciencia, y podría haberse percatado que, mediante alegaciones de ese tipo, él demostraba con toda evidencia que, en efecto, hasta el momento el río era desconocido.
\end{abstract}

F stas palabras fueron escritas por el Conde Francis de Castelnau (1810-1880) y se encuentran en el tomo III de su Histoire du Voyage (1851). ${ }^{1}$ El tono irónico intenta minimizar las críticas que el político y militar brasileño Zeferino Pimentel Moreira Freire (1806-1865) le había hecho en 1846 en relación con un supuesto descubrimiento geográfico. ${ }^{2}$ Pasemos a ver los hechos.

Fecha de recepción: 1ํㅡe diciembre de 2016

Fecha de aceptación: 16 de marzo de 2017

${ }^{1}$ Castelnau, Histoire $d u$ Voyage, t. III, p. 18.

2 Moreira Freire, "Confutação da existência do novo rio", p. 2. 
Entre 1843 y 1847, Castelnau visitó las regiones bañadas por el río Paraguay, al mando de la expedición científica que el gobierno francés envió al interior de América del Sur, empresa que se conoce también como expedición Castelnau. Lo acompañaban el Vizconde Eugène d'Osery (18191846), ingeniero de minas; el médico y botánico Hugues A. Weddell (1819-1877), y el preparador de historia natural Emile Deville (1824-1853); juntos recorrieron la espectacular e inusual ruta que los llevó por tierra y por agua desde Río de Janeiro a Lima y de esta ciudad a Belém do Pará.

Era abril de 1845 cuando la caravana francesa subió el curso del río Paraguay y se encontró con las grandes lagunas Gaiba y Uberaba, y un canal que ligaba las aguas de ambas. Al consultar los mapas de América del Sur de John Arrowsmith y de Adrien-Hubert Brué, con los cuales viajaba, Castelnau constató que éstos informaban poco sobre aquel lugar; según esclarece, en ellos figuraban apenas cuatro o cinco "ríos imaginarios en esa región”. En vista de esto, el viajero consideró que era el primer explorador de las dos grandes lagunas y también pensó que había descubierto un nuevo río, pues, como afirmó, “se trataba de un lugar que jamás había sido visitado por europeos”. 3

Entusiasmado con este hecho, al llegar a Lima, el viajero envió un Relatório al ministro de Instrucción Pública de Brasil, en el que informaba sobre la última parte del trayecto que había realizado - de la provincia brasileña de Mato Grosso, pasando por Bolivia, hasta llegar a la capital de Perú-, sin dejar de comentar del río que, según él, "no era

3 Para este y los demás trechos citados en el parágrafo, véase CastelnaU, "Relatório dirigido ao Sr. Ministro", p. 1. 
conocido por los geógrafos". Siendo así, propuso "que se le dé el nombre de río Pedro II, en homenaje a su majestad imperial", en referencia al emperador de Brasil. ${ }^{4}$

Poco después, ese Relatório apareció íntegramente en la edición del Jornal do Commercio do Rio de Janeiro que circuló el 10 de septiembre de 1846. De esta forma, uno de los periódicos más leídos en la Corte brasileña hacía públicos aquellos comentarios. Pero las cosas no eran exactamente como Castelnau las presentaba.

El singular paisaje lacustre fluvial del interior sudamericano, donde el río Paraguay expande sus meandros y que hoy es conocida como Pantanal, si bien no constaba en ninguno de los dos mapas europeos, ya desde mediados del siglo xviII había sido descrito en texto y mapas. Inicialmente esto había sido hecho en 1754 por los comisarios de la Tercera Partida de Límites, vale decir, por la expedición lusoespañola enviada a América Meridional por orden del Tratado de Madrid (1750); y después, en 1876, por la expedición astronómica portuguesa, liderada por el capitán de ingenieros Ricardo Franco de Almeida Serra (1748-1809) y con la participación de los doctores-astrónomos Francisco José de Lacerda e Almeida (1753-1805); y António Pires da Silva Pontes Lemos (1750-1805), esta última describió minuciosamente y cartografió toda aquella región. ${ }^{5}$

Ocurre que pocos años antes de que Castelnau visitara el interior de Brasil, el militar Zeferino Pimentel Moreira Freire había ejercido el cargo de presidente de Mato Grosso, es

\footnotetext{
${ }^{4}$ Castelnau, "Relatório dirigido ao Sr. Ministro", p. 1.

${ }^{5}$ Las informaciones constan en Almeida Serra, "Diário da diligencia do reconhecimento do Paraguay".
} 
decir, había sido gobernador de la provincia a la que pertenecía el Pantanal, y conocía los diarios y mapas que Almeida Serra y sus compañeros habían producido cuando estuvieron en esas tierras. Así, al leer sobre los "descubrimientos" que Castelnau había hecho en la cuenca paraguaya, de inmediato escribió al propio Journal do Commercio refutando el protagonismo que el viajero francés se atribuía e informando que en la cuenca paraguaya ya no existía ningún río desconocido y que Castelnau no había sido el primer europeo en visitar la región.

Sus opiniones se apoyaban en párrafos del diario y hacían referencia a los mapas que los expedicionarios portugueses habían dejado, los cuales - según informa - se conservaban en los archivos de Cuiabá, la capital de Mato Grosso. Y concluye:

Estoy seguro que si el Sr. conde de Castelnau hubiese tenido a mano el diario y las observaciones astronómicas que existían de los primeros desbravadores que pasaron por ahí, la ciencia se habría beneficiado mucho con las anotaciones que los enriquecería, y yo no me vería en la obligación de reparar este aparte del informe, lo que hago únicamente para corregir ese error de la geografía, sobre todo tratándose de fronteras, donde cualquier duda puede acarrear cuestiones complicadas en el futuro. ${ }^{6}$

Esas críticas rápidamente llegaron a oídos de Castelnau, de modo que en la narrativa que publicó, al describir el viaje por el río Paraguay no se atribuyó el papel de descubridor de ríos ni lagunas, y simplemente dice:

${ }^{6}$ Moreira Freire, "Confutação da existência do novo rio", p. 2. 
Los salvajes llaman de Jequié a este curso de agua. Como no lo encontramos mencionado en ninguna carta geográfica, me felicité por tener la oportunidad de testimoniar mi reconocimiento a Su Majestad el Emperador de Brasil, dándole el nombre de río Don Pedro II. Estaba lejos de imaginar que ese homenaje tan natural llegase a motivar críticas amargas por parte de un coronel brasileño a través del Jornal do Comercio, de Río de Janeiro. En esta hoja declara el referido oficial que el curso de agua al que nos referimos está señalado en un manuscrito existente en los archivos de Cuiabá.7

Y concluye la descripción con la irónica observación de que "sólo los hechos publicados se tienen como adquiridos por la ciencia”, que fue utilizada como epígrafe en este artículo.

Todo indica que, de hecho, durante su paso por Brasil Francis de Castelnau no tenía conocimiento de la expedición que Ricardo Franco de Almeida Serra capitaneó por el paisaje fluvial lacustre del Pantanal. No obstante, el conde viajero ya tenía conocimiento tanto de ese capitán de ingenieros portugués como de los dos astrónomos que lo acompañaban.

En 1843, cuando la caravana francesa llegó a Brasil, Castelnau y sus compañeros pasaron algunos meses en Río de Janeiro. En ese tiempo, el Conde D’Osery tomó contacto con los diarios y mapas producidos por el equipo de Almeida Serra, que se conservaban en los acervos de la capital del Imperio; incluso se llegaron a hacer algunas copias, entre las que estaban los documentos relativos a otro viaje que aquel equipo había realizado en 1782, cuyo destino había sido el

7 Castelnau, Histoire $d u$ voyage, t. III, p. 18. 
río Madeira. Lo curioso es que ese tributario del Amazonas no estaba incluido en el trayecto que la expedición francesa pretendía realizar ${ }^{8} \mathrm{y}$, de hecho, ni Castelnau ni ninguno de sus compañeros llegó a conocer el Madeira. Con independencia de esto, ese río fue incorporado en la obra que Castelnau publicó como resultado de su expedición;' aparece tanto en el texto como entre las cartas geográficas que el viajero produjo. Uno y otro - texto y mapa - se realizaron, precisamente, con base en las informaciones que los franceses extrajeron de los inéditos documentos dejados por Ricardo Franco y sus compañeros.

${ }^{8}$ En cuanto a su ruta, la expedición Castelnau se había impuesto atravesar dos veces el continente; la primera la conduciría de Río de Janeiro por el interior de Brasil y de Bolivia hasta alcanzar la ciudad de Lima; y la segunda, ya de regreso, a partir de la capital peruana, pasando por Cuzco para después descender los ríos Ucayale y Urubamba y, a través de ellos, llegar al Amazonas; a continuación, por ese río llegarían a la ciudad de Belém do Pará para, de ahí, retornar a Europa. Véase Castelnau, Histoire $d u$ voyage, t. I, p. 11, y también Castelnau, "Notice sur l'expédition envoyée".

9 El resultado del viaje fue publicado en París entre 1750 y 1759, en una obra dividida en siete partes, que sumaron 15 volúmenes, con el título general de Expédition dans les Parties Centrales de l'Amérique du Sud: $1^{\mathrm{a}}$ Parte: Histoire du Voyage (6 tomos) 1850-1852; $2^{\mathrm{a}}$ Parte: Vues et scènes (Atlas con 60 planchas y textos), 1852; $3^{\mathrm{a}}$ Parte: Antiquités des Incas et autres peuples anciens (Atlas con 60 planchas e textos), 1854; $4^{\mathrm{a}}$ Parte. Itinéraires et coupe géologique à travers le Continent de l'Amérique du Sud (Atlas con 76 cartas dobles y textos), 1853; $5^{\text {a }}$ Parte: Géographie, des parties centrales de l'Amérique du Sud (Atlas con 30 cartas dobles y textos), 1854; $6^{a}$ Parte: Chloris andina. Essai d'une flore de la région alpine des Cordillères de l'Amérique du Sud / par H.A. Weddell / Botanique (2 volúmenes, con 96 planchas), 1855-57; $7^{\text {a }}$ Parte: Animaux nouveaux ou rares recueillis pendant l'expédition/Zoologie (3 volúmenes, con 125 planchas), 1855-1859. 
En este artículo se abordará la relación que la expedición Castelnau estableció con el material legado por la comitiva científica comandada por el ingeniero Ricardo Franco de Almeida Serra, que a finales del siglo xviII visitó y describió científicamente los principales ríos de la cuenca amazónica. Se busca observar cómo los visitantes extranjeros se apropiaron del conocimiento producido por el equipo portugués, tomando como objeto de análisis el río Madeira.

Para efectos de la exposición, inicialmente haremos una breve presentación de ese río, para enseguida tratar de las dos expediciones. A continuación, como interludio, se abrirá una digresión sobre mapas y cartografía de viajes científicos para, de ese modo, llegar al mapa del río Madeira que Castelnau produjo y publicó.

\section{EL MADEIRA, UN GRAN RÍO}

El Madeira es uno de los grandes cursos fluviales de nuestro planeta y uno de los principales tributarios del Amazonas. Sus aguas nacen en la cordillera de los Andes, en territorio hoy boliviano, donde recibe el nombre de Beni. Aún en Bolivia, el Beni gana cuerpo al recibir diversos afluentes, de los cuales el mayor es el Madre de Dios. Pero es al encontrarse con el Mamoré - cuyas nacientes también se localizan en los Andes bolivianos - que se transforma en el Madeira. ${ }^{10}$ Ese nombre, de "río de la Madera", le fue dado por los

10 Sabemos - de acuerdo con lo que menciona Ramirez, "Etnônimos e topônimos" - que las cabeceras del río Madeira aún hoy se configuran como un problema; en este artículo consideramos al río Madeira desde el encuentro de las aguas del Beni con el Mamoré hasta su desembocadura en el Amazonas. 
lusobrasileños a mediados del siglo xviı debido a la gran cantidad de árboles caídos que transportaban sus aguas.

\section{Figura 1}

MAPA FÍsICO DE BRASIL (DETALLE)

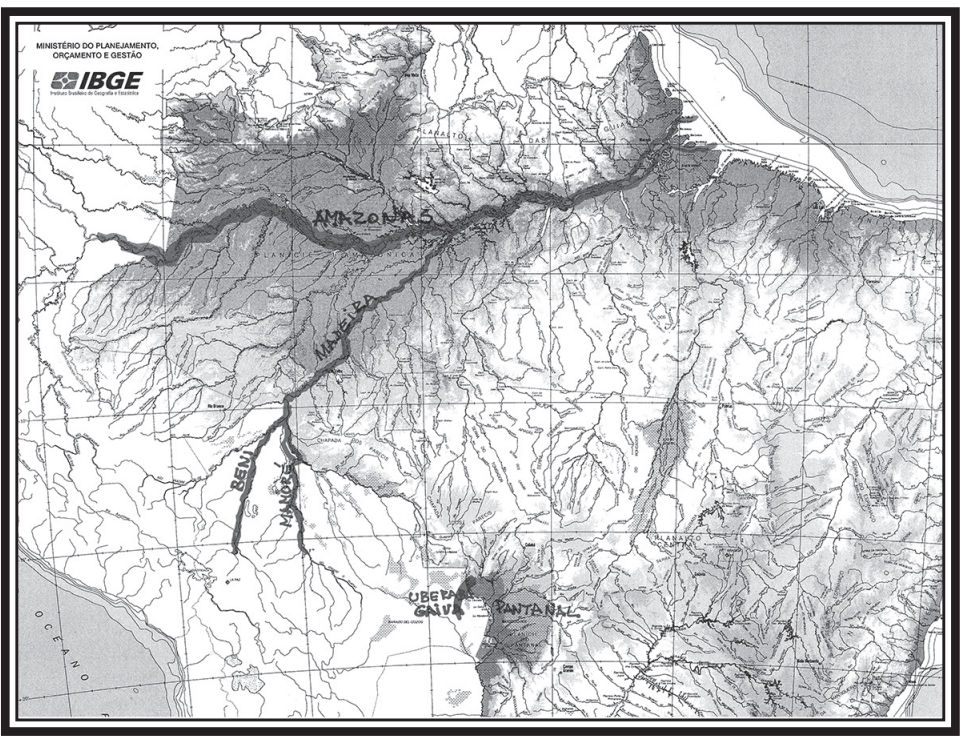

Las regiones coloreadas señalan el río Beni-Madeira y la región del Pantanal donde se localizan las lagunas de Gaiba y Uberaba.

FuENTE: Instituto Brasileiro de Geografia e Estatística

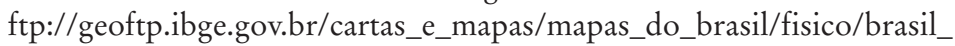
fisico5000k_2007.pdf La imagen contiene intervenciones de la autora.

El Madeira es clasificado como un río aún en formación, siendo en parte un río de la planicie y en parte también un río del altiplano. Mientras fluye por el altiplano, su cuerpo fluvial corre sobre afloramientos de rocas cristalinas que provocan 17 accidentes geográficos, entre rápidos del río 
y cascadas. Después, cuando pasa a ser un río de planicie, corre libremente sin ofrecer obstáculos a la navegación.

A finales del siglo xv, por disposición del Tratado de Tordesillas (1494), la región bañada por el Beni-Madeira quedó bajo dominio de los españoles $y$, de hecho, las primeras noticias sobre ese río fueron dadas por los jesuitas que, a mediados del siglo Xvir, establecieron misiones en la provincia de Mojos, en el Alto Perú. Esos religiosos solían visitar el Madeira en busca de zarzaparrilla, cacao, anís y otras "drogas del sertón”. Los lusos, a su vez, sólo tomaron conocimiento de su curso un siglo más tarde, cuando, viniendo de São Paulo, avanzaban en sentido oeste procurando esclavizar indios y extraer metales preciosos y llegaron, en un primer momento, a la región que le dieron el nombre de Minas del Cuiabá, en la cuenca del Paraguay, y después, siempre continuando en sentido oeste, a otro lugar aurífero que denominaron de Mato Grosso, ya en la cuenca amazónica. ${ }^{11}$

Para organizar el dominio sobre los territorios que conquistaba, en 1749 el gobierno metropolitano portugués creó la capitanía de Mato Grosso y Cuiabá y fundó Vila Bela da Santíssima Trindade, con la categoría de villa capital, localizada en los márgenes del río Guaporé (tributario del Mamoré). Con el propósito de hacer efectiva la comunicación y el comercio de esa villa con el resto de la América Portuguesa y con Lisboa, los cursos de los ríos Guaporé, Mamoré, Madeira y Amazonas fueron transformados en caminos, para, a través de ellos, llegar a la ciudad de Belém do Pará y de ahí al Atlántico. ${ }^{12}$

${ }^{11}$ Sobre los viajes en el río Madeira, consúltese Pontes Pinto, Hidrovia do Grão-Pará; Almeida, "A viagem de José Gonçalvez da Fonseca".

${ }_{12}$ Sobre ese asunto véase Correa Filho, História de Mato Grosso, y Canavarros, O poder metropolitano. 
Durante la segunda mitad del siglo Xviı, fue por esa vía fluvial que Vila Bela empezó a recibir mercaderías procedentes del otro lado del océano Atlántico y a dar salida, para Lisboa, al oro que extraía. Para eso organizaba caravanas comerciales, conocidas como "monzones del norte". ${ }^{13}$ Pero había más; con esa ruta, el Estado portugués procuraba consolidar su presencia en la región que conquistaba del territorio colonial español en el Alto Perú y que, por esa época, se estaba convirtiendo en la frontera lusocastellana.

Pero ese camino fluvial no era una ruta rápida, ni tampoco tranquila o constante. En los márgenes del Madeira y de sus tributarios vivían decenas de pueblos y naciones indígenas que ofrecían una vigorosa resistencia a la presencia colonizadora, defendiendo con bravura sus territorios. A su vez, los accidentes naturales que se presentaban, tales como los rápidos y las cascadas -17 en el río Madeira y 5 en el Mamoré-, dificultaban la navegación y, además, el viajero se veía expuesto a convivir con numerosas y variadas fiebres, algunas de las cuales eran letales. Por otro lado, los viajes debían realizarse respetando la estacionalidad de las aguas, siendo necesario esperar la mejor ocasión - razón por la que las caravanas eran llamadas monzones-, vale decir, la época en que las aguas de los ríos estuvieran en su volumen medio.

Al depender del tamaño de la caravana y de la carga que llevara, un viaje de ida y vuelta de Pará a Mato Grosso demoraba entre seis meses y un año, y para ser lucrativa, una monzón debía estar compuesta por lo menos de

13 Sobre las monzones del norte véanse Davidson, "How the Brazilian West Was Won”; Amaral Lapa, Economia colonial. 
10 canoas. En esos viajes, los barcos de tamaño mayor y más pesados enfrentaban mucha dificultad para superar los accidentes geográficos; a veces posible pasar con los barcos a media carga, pero otras, sólo se conseguía pasar con los barcos vacíos. Pero en los accidentes donde el curso de las aguas se veía trastornado con más violencia era necesario sacar las embarcaciones del río y llevarlas por tierra a través de caminos conocidos como "varaderos" $y$, una vez traspuesto el accidente, colocarlas nuevamente en el río. En cualesquiera de las situaciones, las mercaderías y demás objetos los cargaban por tierra los indios o los esclavos negros.

A finales del siglo xviII, ese difícil camino recibió la visita de dos caravanas científicas enviadas por el gobierno portugués. Primero fue la tercera Partida de Límites que, entre los años 1781 y 1782, bajo el comando de nuestro ya conocido ingeniero Ricardo Franco de Almeida Serra viajó de Belém a Vila Bela; después fue la oportunidad de la expedición científica, más conocida como "viaje filosófico", capitaneada por el filósofo naturalista Alexandre Rodrigues Ferreira (1783-1792). Si bien esas expediciones fueron concebidas con propósitos diferentes, ambas debían estudiar el camino e indicar soluciones para mejorar el recorrido, pues era necesario colonizar y explorar la región y, con esto, consolidar la frontera, tanto así que J. J. Codina y J. J. Freire, dibujantes del "viaje filosófico", registraron a lápiz y acuarela todos los accidentes geográficos de los ríos Madeira y Mamoré. Se trata de la primera representación visual de aquel paisaje acuático, la cual fue ejecutada con el fin práctico de mostrar las cascadas y los rápidos en las distintas épocas del año, de acuerdo con 
la estacionalidad de las aguas y, con esto, indicar la mejor manera de vencer esos obstáculos. ${ }^{14}$

Pero aquí nos interesa la expedición al río Madeira, comandada por el capitán de ingenieros Ricardo Franco de Almeida Serra.

\section{CIENCIAS Y FRONTERA EN LAS AGUAS DEL MADEIRA}

La expedición portuguesa que visitó el río Madeira entre los años 1781 y 1782 fue montada con el título de $3^{\text {a }}$. División de Límites portuguesa o Partida de Límites Norte; además del citado jefe Almeida Serra, también formaban parte de ella el capitán de ingenieros José Joaquín Ferreira y los astrónomos y matemáticos António Pires da Silva Pontes y Francisco José de Lacerda, hombres de un amplio saber, educados de acuerdo con los preceptos del iluminismo portugués. Cabía a ese equipo esperar la llegada de los colegas españoles para, conjuntamente, realizar el reconocimiento de la región que, por disposición del Tratado de San Ildefonso (1777), se configuraba como la línea de frontera.

Pero como los españoles tardaban en llegar, las autoridades metropolitanas decidieron aprovechar a sus profesionales para realizar una serie de viajes con el fin de que ellos reconocieran las áreas fronterizas. Fue con ese propósito que en septiembre de 1781 el equipo de Ricardo Franco se adentró en las aguas del Madeira navegando río arriba.

El viaje de Pará a Mato Grosso dilató cinco meses y se hizo en seis canoas. Además de los cuatro demarcadores, formaban parte de ese viaje un capellán y un cirujano,

${ }^{14}$ Costa, "Paisagens narrativas", pp. 64-77. 
responsables de los remedios espirituales y los físicos, respectivamente, y 16 soldados liderados por un sargento y dos cabos, cuya función era defender al grupo. Para la tripulación se contrataron indígenas que actuarían como ¿cargadores, guías?, y remeros que, a lo largo del trayecto, llegaron a sumar nada menos que 100, "de los cuales murieron treintaiséis". 15

Mientras viajaba, haciendo uso de los más modernos aparatos de medición, la caravana llevaba a cabo observaciones y levantaba las informaciones necesarias para dibujar mapas y escribir diarios. En esos registros - tanto en los escritos como en los cartográficos-, ingenieros y astrónomos establecían con precisión latitud y longitud, indicaban las cascadas y los rápidos, y señalaban las maneras para vencerlos. Explicitaban cómo las canoas debían pasar, si llenas, vacías o a media carga, y el tiempo que cada paso requería; indicaban también la velocidad de la corriente del Madeira, daban nombre y describían sus afluentes, las islas y las lagunas, así como la existencia de playas; localizaban e identificaban los pueblos indígenas, señalando sus territorios y el grado de relación que tenían con los colonizadores y, también, los productos naturales que podrían explotarse, entre otras informaciones relevantes. ${ }^{16}$ De este modo, de hecho, llevaban a cabo un verdadero catastro geográfico, económico y social.

15 APMT, "Diário da viagem, que a expedição", libro 03, f. 114v.

16 Véase APMT, "Diário da viagem, que a expedição", en Livro de Registro; Lacerda e Almeida, Diario de Viagem do Dr. Francisco Jose"; POnTEs, "Diário da expedição que partiu". 
Figura 2

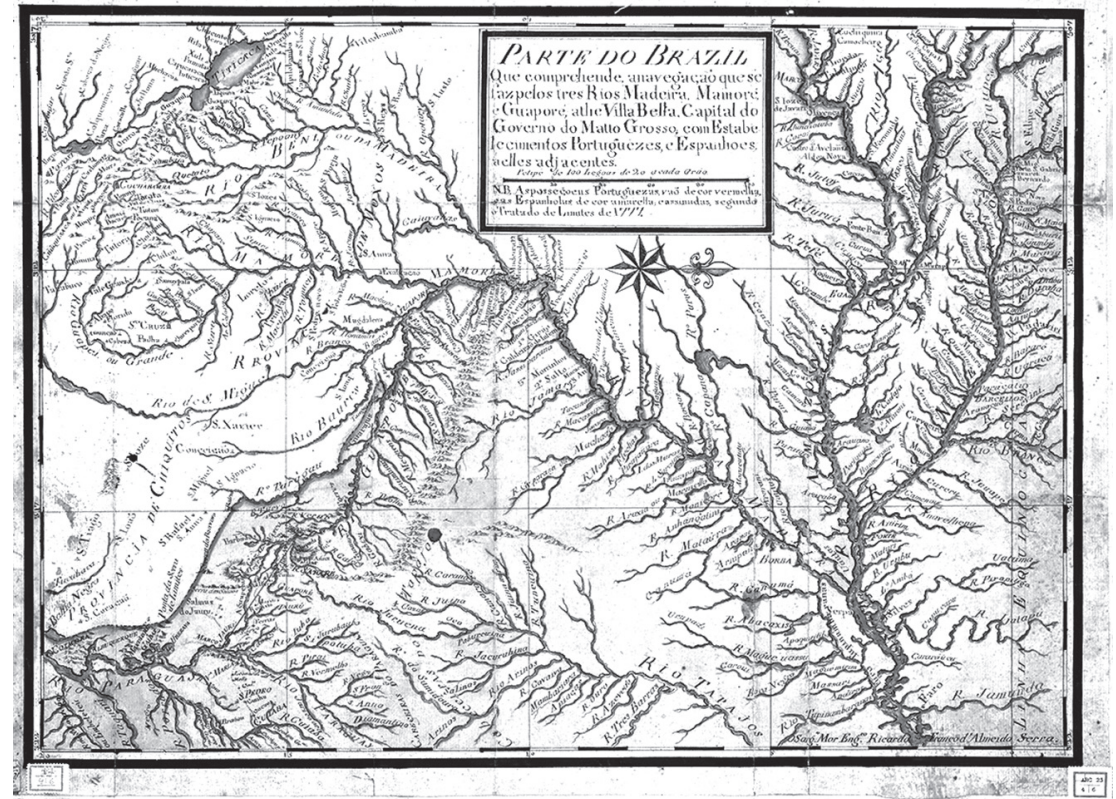

Ricardo Franco de Almeida Serra (1748-1809)

Parte do Brazil que comprebende a navegação que se faz pelos tres Rios Madeira, Mamoré e Guaporé, athe Villa Bella, Capital do Governo do Matto Grosso, com Estabelecimentos Portuguezes, e Espanboes, aelles adjacentes. Década de 1780

Tinta y acuarela sobre papel, $43.6 \times 60.8 \mathrm{~cm}$

Este es uno de los mapas producidos por el equipo comandado por Ricardo Franco, en el cual se señalan nominalmente todos los acidentes del Madeira y del Mamoré.

Fuente: Biblioteca Nacional do Rio de Janeiro - ARC.023,04,006Cartografia. ${ }^{17}$

17 Agradezco a la doctora Maria Dulce Faria, jefe de la Sección de Cartografía de la Biblioteca Nacional de Río de Janeiro, que con su constante buena voluntad me facilitó el acceso a ese mapa y puso a mi disposición la copia que aquí se publica. 
Sin embargo, este valioso material - como también es el caso de aquel relativo al viaje que Ricardo Franco hizo al Pantanal-, por razones de sigilo, no se dio a conocer ni durante la colonia ni cuando Brasil pasó a ser un imperio. De ese modo, el acceso al conocimiento gestado por esas expediciones quedó circunscrito a los funcionarios del Estado.

Castelnau, sin embargo, sí pudo consultar esas informaciones. Como ya se observó, en 1843, durante la permanencia del equipo francés en Río de Janeiro, él y D’Osery tuvieron fácil acceso a las instituciones y autoridades, que les permitieron consultar acervos y conseguir "reunir muchos documentos sobre la geografía de Brasil”. En palabras del viajero:

Todas las instituciones científicas en Río de Janeiro se abrieron para nuestras investigaciones, y muchos documentos fueron puestos a nuestra disposición. Nos fue permitido hacer copias de las cartas guardadas en el Ministerio de Guerra, en la Biblioteca del Emperador y en la del Instituto [se refiere al Instituto Histórico e Geográfico Brasileiro-IHGB]. ${ }^{18}$

Esto permitió que los expedicionarios obtuvieran un abundante material a partir del acervo de los bien capacitados funcionarios portugueses que habían conocido en el propio lugar las tierras del interior y habían dejado detalladas descripciones en diarios, memorias y mapas. Entre los materiales que fueron copiados por Castelnau se encontraban, precisamente, los diarios y los dibujos del río Madeira que Ricardo Franco y sus compañeros habían producido.

18 Castelnau, Histoire du voyage, t. I, pp. 120-121. 
Pero, ¿cuál era el interés de la caravana francesa por ese río? Para entender esa cuestión es necesario atender las premisas que impulsaban las tareas de la expedición francesa.

\section{LA EXPEDICIÓN CASTELNAU}

Se trata de uno de los proyectos promovidos por el gobierno instituido en Francia por la Monarquía de Julio (18301848). En el ejercicio del poder, con una base constitucional y siendo reconocidamente liberal, Luis Felipe de Orleans (1773-1850) favoreció de manera considerable a la burguesía y ésta le dio su apoyo. Gracias a ello, durante su reinado, los franceses se reorganizaron políticamente, lo que permitió que Francia volviera a la carrera industrial y reconstruyera una marina en condiciones de competir con los ingleses y los belgas en la supremacía tanto militar como económica y diplomática en otros espacios. El objetivo principal eran las jóvenes naciones sudamericanas que entonces se presentaban como lugares atractivos y codiciados. ${ }^{19}$ Esto ocurría en un momento en que, libre del dominio colonial, la antigua Iberoamérica pasaba a ser vista por Europa como un lugar de oportunidades, a la espera de aquellos que, con espíritu liberal, tomaran la iniciativa de explotarlas. Pero para esto era necesario un conocimiento real de sus potencialidades.

Así pues, en la primera mitad del siglo xIx, Francia procuraba conocer los nuevos estados de América Meridional por medio de viajes científicos, buscando crear lazos de

19 Sobre ese asunto véase KirchHeImer, Voyageurs francophonesen, 2009. 
dependencia comercial y cultural. ${ }^{20}$ Reconocer geográficamente aquellos territorios y sus potencialidades y verter estas informaciones de manera racional a un lenguaje tanto verbal como cartográfico constituía uno de los propósitos. Y fue exactamente esto lo que Castelnau resumió al llegar a Lima, afirmando que su expedición tenía por objeto "hacer descubrimientos geográficos y procurar nuevos productos para el comercio". ${ }^{21}$

Fue con ese interés que Castelnau y sus compañeros, todos funcionarios de Estado y vinculados a instituciones y academias científicas de Francia, recorrieron los tortuosos caminos del interior sudamericano y a lomo de mula atravesaron el altiplano central brasileño y la cordillera de los Andes, así como en canoas navegaron por los cursos de grandes ríos como el Tocantins, el Araguaia, el Paraguay, el Ucayale, el Urubamba y el Amazonas, y al final publicaron los resultados en la gran obra en siete partes que recibió el título general de Expédition dans les Parties Centrales de l'Amérique du Sud.

Para el estudio de la relación de la expedición Castelnau con el río Madeira trabajamos con la narrativa que el viajero publicó bajo el título de Histoire du voyage (1a. Parte, 6 tomos) y en el volumen Géographie des parties centrales de l'Amérique du Sud (7a. Parte, 1 tomo). La narrativa quizá sea la parte más leída y más conocida de Expédition, mientras que la Géographie raramente es citada. Ésta se configura como un pequeño atlas compuesto por 30 mapas dobles expuestos como planchas, antecedidos por una Introducción,

20 Véase Huerta, “Le Voyage aux Amériques”, pp. 73-93.

21 Castelnau, "Relatório dirigido ao Sr. Ministro”, p. 1. 
en la que el autor presenta la obra y hace breves observaciones sobre cada uno de los mapas. Es en las planchas donde el viajero expone su visión del interior sudamericano.

Es interesante constatar que en los estudios sobre los viajes científicos se ha prestado poca atención a la cartografía, a pesar de que son pocas las expediciones científicas que no hayan producido mapas, y en el caso de la expedición Castelnau esto no fue diferente.

\section{VIAJEROS Y MAPAS}

No debe extrañar la presencia de mapas en el conjunto de la obra que un viajero publica con los resultados de una expedición realizada por tierras que eran vistas como distantes y desconocidas. Se sabe de la gran importancia que el levantamiento cartográfico tuvo para las empresas científicas. El mapa, junto con el texto escrito y la imagen, constituye una de las principales formas narrativas utilizadas en publicaciones relativas a los viajes científicos. De hecho, en el conjunto del material gestado por una expedición, los mapas se configuran como una tercera narrativa, la narrativa cartográfica (siendo la primera la textual y la segunda la iconográfica). Fue por medio de los mapas producidos durante los viajes de circunnavegación realizados por James Cook (1728-1779) y Louis de Bougainville (1729-1811) que en el siglo XVIII se conocieron con detalle la fisionomía y las dimensiones generales - tanto continentales como insulares - de nuestro planeta. Fue esto lo que posibilitó, al mismo tiempo, conocimiento, dominio y explotación.

En las expediciones dentro de los continentes, la cartografía no fue menos importante. Alexander von Humboldt 
(1769-1859), por ejemplo, se empeñó en la producción de mapas que mostraran las regiones que visitó, y en su gran obra incluyó el Atlas géographique et physique des régions équinoxiales du nouveau continent, publicado en 1814. Ciertamente, en el caso de la expedición Castelnau esto no sería diferente, pues es mediante los dibujos cartográficos que se puede, entre otros objetivos, determinar la localización de ciudades y villas, de los cursos de los ríos, en fin, es por medio de los mapas que se consiguen los datos de un lugar, haciendo posible el retorno y el dominio. A ese respecto, como ya destacó Fernando Bouza:

[...] el mapa humaniza el territorio, primero, porque lo reduce a escala humana y, en segundo lugar, porque convierte el espacio que figuradamente representa en una dimensión que deja de ser una entelequia para convertirse en una superficie sobre la que es posible razonar y actuar. En este sentido, el mapa ha sido un signo de la modernización del pensamiento humano y un medio de la definitiva configuración política y económica de nuestras sociedades. ${ }^{22}$

El hecho de que, en la obra con los resultados del viaje publicada por Castelnau, los mapas hayan merecido una de sus partes, demuestra de manera elocuente que esa expedición atribuyó también mucha importancia a la construcción cartográfica, reconociéndola como una herramienta de actuación y dominio. Es más, pone en evidencia que la caravana francesa - con independencia de haber realizado los trabajos propios de ese tipo de empresa (reunión de datos de los tres reinos de la naturaleza, descripción de los lugares

${ }^{22}$ Bouza, “Introducción”, p. 15. 
y de sus habitantes) - dedicó gran atención al estudio de la geografía y la geología de los lugares que visitó. ${ }^{23}$ Cabe destacar que, al realizar el largo trayecto por el interior sudamericano, esos naturalistas se proponían conocer y hacer mapas de los grandes ríos, en especial de las fuentes de los afluentes meridionales del Amazonas, y estudiar los productos del Amazonas y las facilidades para su exportación. ${ }^{24}$

¿De qué manera se podrían realizar tales tareas sin levantar mapas? Como ya observó J. B. Harley, las cartas geográficas son valiosos instrumentos de poder; permiten la representación gráfica de realidades espaciales que el hombre no llegaría a percibir sin su auxilio. Pero las cartas no responden únicamente al conocimiento geográfico. Detrás de un cartógrafo, observa ese autor, hay un conjunto de relaciones de poder que crean sus propias formas de aprehensión de las realidades espaciales. ${ }^{25} \mathrm{Y}$ las cartas del interior sudamericano publicadas por Castelnau no escapan a esa directiva, tanto es así que, en la Géographie, los espacios visitados no se muestran de forma ecuánime. En ella Brasil es el principal personaje, seguido por la República de Bolivia y, por último, de Perú, país que, por lo demás, se muestra apenas de forma somera. Las tierras brasileñas figuran en más de la mitad de las cartas, con énfasis en las regiones interiores que recorrió la expedición - Minas Gerais, Goiás y Mato Grosso - y los grandes cauces fluviales, principalmente aquellos pertenecientes a los tributarios del Amazonas. Además, ese atlas representa lugares de Brasil en los

${ }^{23}$ Costa, "A paisagem do Brasil representada por Francis de Castelnau”, pp. 331-350.

24 Castelnau, Histoire du voyage, t. I, pp. 11-12.

25 Harley, La nueva naturaleza de los mapas. 
que la expedición francesa no estuvo, como es el caso de las tierras bañadas por el río Madeira.

Respecto a la representación de Bolivia, los mapas incluidos en la Géographie traen básicamente la región fronteriza, vale decir, el área que limitaba con el Imperio brasileño, correspondiente a los antiguos espacios españoles, conocidos como Oriente Boliviano. Esa región fue detallada en nada menos que 11 cartas.

Perú es el gran ausente. En la Géographie, las tierras peruanas no fueron objeto de ningún mapa específico, de modo que aparece únicamente en la gran Carte des parties centrales de l'Amérique du Sud. Todo nos lleva a creer que la ausencia del territorio peruano, que efectivamente fue visitado por la expedición, está directamente relacionada con los motivos que llevaron a Castelnau a incluir la región del río Madeira, que no visitó.

Castelnau explica esa laguna por la pérdida de material ocurrida en 1846, cuando el ingeniero D’Osery fue asesinado por sus guías en las proximidades de Lima. Además, recuerda que la última parte del viaje por Perú fue la más difícil. De hecho, el descenso de los veloces y accidentados ríos Ucayale y Urubamba - tributarios del Amazonas - no permitió que los viajeros realizaran ninguna tarea científica, pues, según comenta Castelnau, en ese recorrido se vieron obligados a "renunciar a los trabajos científicos" en beneficio de no abandonar el viaje. ${ }^{26}$

Pero en la propia narrativa del viaje hay referencias a las remesas de materiales realizadas durante los movimientos, como ocurrió, por ejemplo, en las provincias brasileñas de

${ }^{26}$ Castelnau, Géographie, p. v. 
Goiás y Mato Grosso, y también en Santa Cruz de la Sierra, en Bolivia. Fue gracias a esos envíos realizados en tránsito que, tal como el viajero señala en la "Introducción" de la Géographie, gran parte de sus anotaciones se recuperaron y se utilizaron para la elaboración de la mayoría de los mapas. ${ }^{27}$ No obstante, por razones obvias, esos datos no incluyen el área peruana.

Aun así, nada justifica la ausencia de Perú en el conjunto de las cartas publicadas en la Géographie. Pensamos, en cambio, que sí hubo falta de motivación, pues, como acertadamente observó Claude Boudreau: “[...] son pocos los mapas que fueron concebidos sin una finalidad determinada, ya que éstos suelen responder a necesidades específicas" ${ }^{28} \mathrm{Y}$ en relación con Perú fue esto precisamente lo que no ocurrió.

Ya señalamos que uno de los principales objetivos de la expedición era estudiar los productos del Amazonas y verificar las facilidades para su salida. Ocurre que los peligros y obstáculos vividos en el curso de la travesía de los veloces y accidentados Ucayale y Urubamba mostraron a Castelnau que esos ríos no eran adecuados para que se estableciera una vía regular de navegación y comercio, lo que redujo el interés que podría tener en ellos.

Lo contrario parece haber ocurrido con el Madeira. Tal como el Ucayale y el Urubamba, ese río también es tributario del Amazonas y asimismo presentaba un cauce bien accidentado. Pero su propia historia contaba que durante décadas sus aguas habían servido como ruta regular para

27 Castelnau, Géographie, p. v.

28 Boudreau, L'Analyse de la carte ancienne. 
la comunicación y el comercio, vinculando el interior del continente al Amazonas, y de ahí al Atlántico. Esa ruta fue utilizada por los lusobrasileños y también vislumbrada del lado español. Sí, Castelnau supo de esto al tener contacto, en Bolivia, con los escritos que Thaddaeus Haenke (17611817) - botánico de origen checo que participó en el viaje de circunnavegación español, más conocido como expedición Malaspina. En abril de 1799, Haenke, quien se había establecido en el Alto Perú, propuso a D. Francisco de Viedma, entonces intendente de Cochabamba, que abriera un camino fluvial desde el interior hasta las aguas del Amazonas.

Su proyecto fue presentado en los Informes sobre las ventajas que pueden resultar al Estado con la libre navegación de los ríos de la Madera y del Amazonas para España en el comercio de los frutos de esta provincia. ${ }^{29}$ Ahí Haenke describe el río Beni y también el complejo fluvial de la región fronteriza, y muestra las ventajas que los españoles tendrían al utilizar el río Beni-Madeira como ruta comercial. Para él, la única dificultad radicaría en la "oposición tenaz de la Nación Portuguesa tan celosa de sus intereses”, pero opina que - en vista del Tratado de Paz que los portugueses estaban firmando con Francia - el problema sería fácilmente sorteado. Todo demuestra, sin embargo, que el gobierno español no le hizo caso a esa propuesta.

En los primeros años del siglo xix, los lusobrasileños también perdieron interés en esa vía, de manera que a inicios de ese siglo la navegación comercial por el Madeira fue

${ }^{29}$ AGN, ms. 138; Thaddews Haenke, Informes sobre las ventajas que pueden resultar al Estado. Posteriormente ese escrito fue publicado con el título de "Memoria sobre los ríos navegables que fluyen al Marañón". 
prácticamente abandonada. Por un lado, el traslado de la capital de Mato Grosso - de Vila Bela para Cuiabá (en la cuenca platina) - tuvo como consecuencia que los lusobrasileños perdieran interés por esa ruta amazónica y, por otro, con el proceso de independencia, la República de Bolivia se vio envuelta en difíciles cuestiones internas.

Pero a mediados del siglo XIX se presentaba como una opción adicional entre los objetivos que conducían los trabajos de la expedición francesa, más aún, después de que Castelnau tuvo conocimiento de los Informes de Thaddaeus Haenke, dado que el botánico indicaba que el camino podría tener inicio en Bolivia.

Debe tenerse en cuenta también que se trataba de un espacio que aún no había sido debidamente reconocido por la ciencia europea. Los mapas que circulaban entonces mostraban esa región de forma genérica, tenían imprecisiones tanto en lo que se refiere al curso del Madeira como a sus tributarios; faltaban datos generales y también de su entorno. Incluso en la carta de "El alto curso del río Madeira con los países colindantes" [Das obere Stromgebiet des Rio Madeira, nebst den angränzenden Ländern], que los viajeros bávaros J. B. von Spix y C. F. Ph. von Martius - que estuvieron en la Amazonia en 1819- publicaron en 1827-1828 en su Atlas, muestra apenas las aguas del Beni hasta su encuentro con el Mamoré, o sea, antes de que se constituya el río Madeira. ${ }^{30}$ Esas circunstancias demuestran que uno de los mayores ríos sudamericanos carecía de representación cartográfica que permitiera una aproximación a su geografía. Así, el hecho de llevar al público informaciones bien circunstanciadas

${ }^{30}$ Spix y Martius, Atlas zur Reise in Brasilien, plancha sin número. 
sobre un río con tal historia ciertamente daría a Castelnau algún protagonismo; y el que su expedición no lo hubiese visto ni hubiera viajado por las aguas de este gran tributario del Amazonas no impedía que lo incluyera en la obra que publicaba, considerando, por lo demás, que tenía en sus manos el material que los expedicionarios lusitanos habían producido en el lugar y que se conservaban inéditos.

Fue exactamente esto lo que hizo Castelnau. Se sirvió de los diarios y mapas que Ricardo Franco y sus compañeros habían producido y con ellos escribió el capítulo XXX de la Histoire $d u$ voyage y compuso la Carte $d u$ cours $d u$ rio Madeira, depuis son embouchure au rio Mamoré, publicada en la Géographie. Pero en ese caso, al tratar del río Madeira, el viajero no se atribuyó el papel de descubridor. Quizá inducido por las críticas que recibió en 1846, tanto en la narrativa como en el mapa aludió a sus fuentes y reconoció la deuda científica contraída con los conocimientos coreados por los ingenieros y astrónomos portugueses.

\section{CASTELNAU Y LA REPRESENTACIÓN DEL RÍO MADEIRA}

El interés del equipo francés por el río Madeira despertó ya durante la estadía en Río de Janeiro, cuando tuvo contacto con las noticias sobre las caravanas llamadas monzones del norte y pudo consultar mapas, memorias manuscritas, descripciones impresas y demás materiales que cayeron en sus manos acerca de ese antiguo camino fluvial. Perspicaz, el conde inmediatamente reconoció la importancia de ese río como camino potencial y también como fenómeno geográfico; explicita su percepción del gran tributario del 
Amazonas en el inicio del capítulo correspondiente, donde escribió:

El río Madeira es el principal de los afluentes del río Amazonas, un río cuyo estudio ofrecería el mayor interés para Brasil, antes de que la capital de Mato Grosso fuera trasladada para Cuiabá. Es muy probable que un día los productos de la región caliente de Bolivia y Perú, situada al este de la cordillera, puedan seguir el curso de ese río y no dudo que se torne el centro de un inmenso comercio. ${ }^{31}$

Ya en esa primera aproximación se pone en evidencia el valor utilitario y geográfico que el viajero atribuye al río Madeira, y que es el mismo que se encuentra en la Carte du cours du rio Madeira depuis son embouchure jusq'au rio Mamoré.

${ }^{31}$ Castelnau, Histoire $d u$ voyage, t. III, p. 119; énfasis de la autora. 
Figura 3

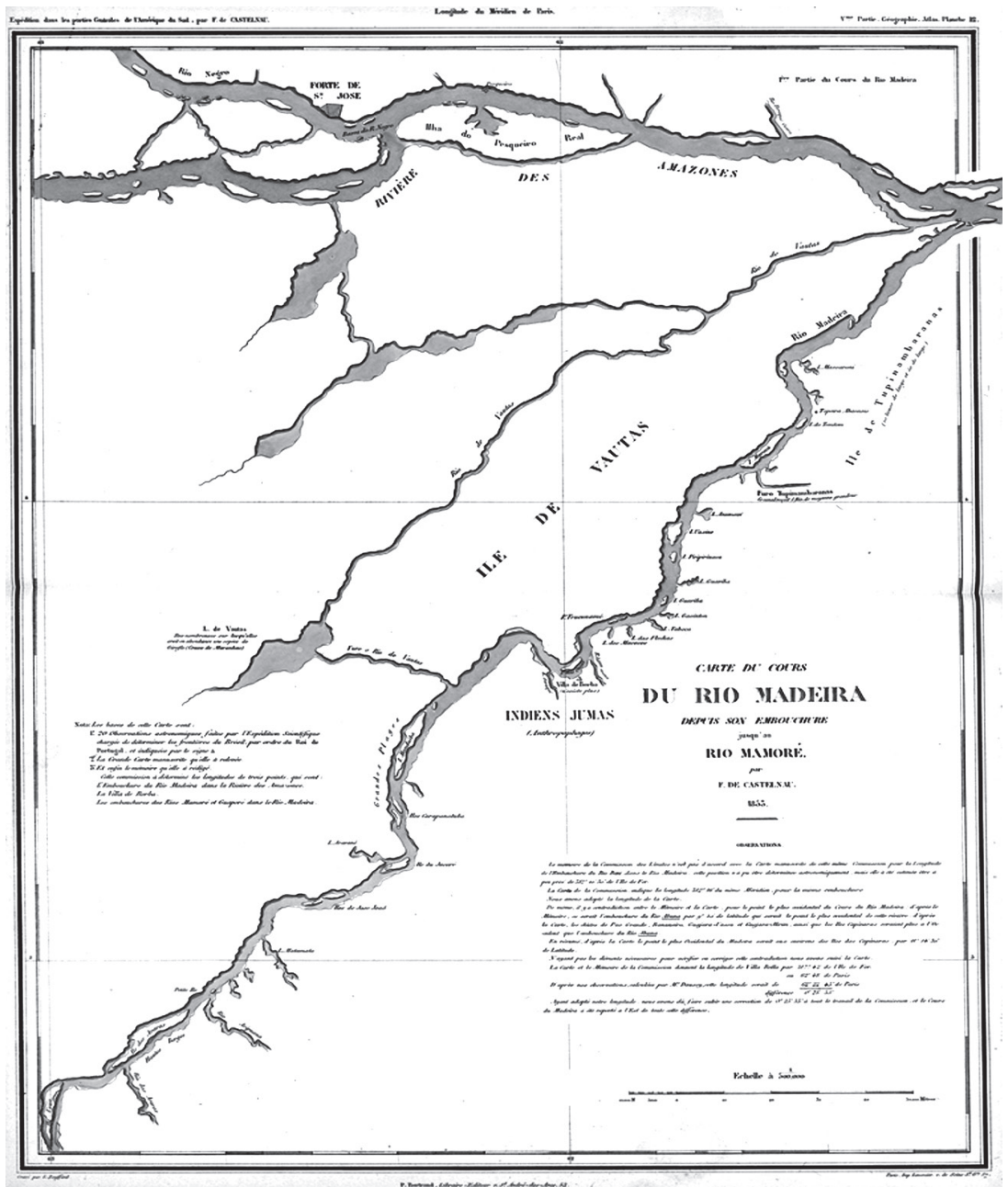

Carte du cours du rio Madeira depuis son embouchure jusq'au rio Mamoré; 1853 . Litografía, $53.4 \times 41.0 \mathrm{~cm}$. 
Figuras 4 y 5

NAVIGATION DU RIO MADEIRA
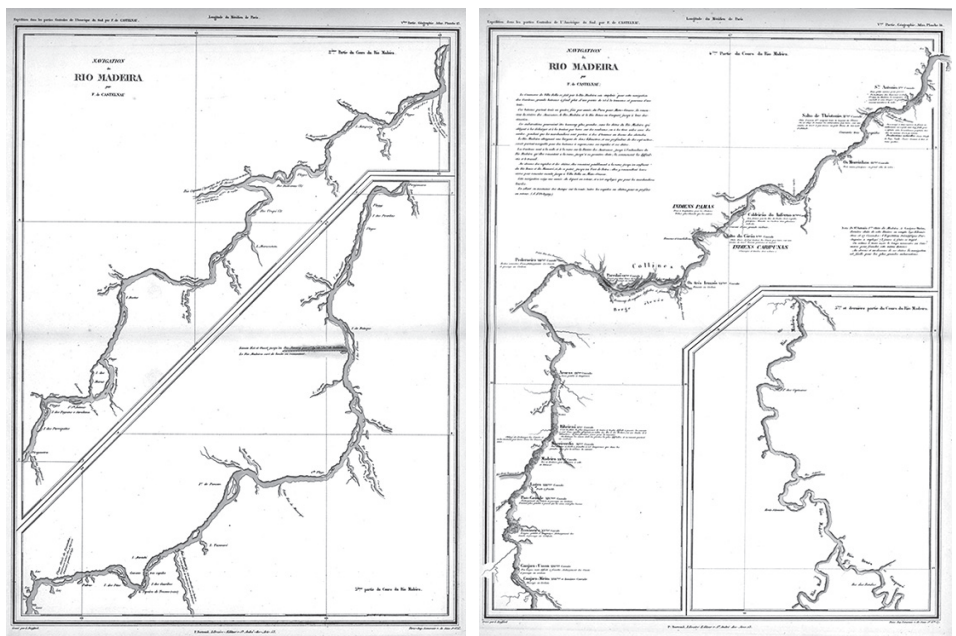

Litografía, $54.2 \times 30.2 \mathrm{~cm}$.

Fuente: Castelnau, Géographie, planchas 12, 13 y 14.

Se trata de un mapa dividido en tres partes consecutivas que se muestra en las planchas 12, 13 y 14 de la Géographie; la primera recibe el nombre general que se dio al mapa y las otras dos llevan el título de Navigation du rio Madeira, lo que, por sí solo, subraya la intencionalidad de la carta. La cartela colocada en la plancha 12 anuncia que su autor es Francis de Castelnau y que fue dibujada en 1853.

La Carte presenta una composición simple, en la que se destaca exclusivamente a los ríos. Éstos aparecen en una delicada tonalidad azul que, además de los toques de amarillo que indican los lugares con playas, son los únicos colores utilizados. Como recurso adicional, el autor utilizó pequeñas cajas 
de texto, en las que expone los datos o hechos que considera relevantes para la comprensión del lugar representado, específicamente en lo que se refiere al comercio y la navegación. Para su elaboración se sirvió de los materiales de la expedición portuguesa, pero también de otras fuentes. Por ejemplo, para situar la navegación, inmediatamente debajo del título de la plancha 14 utilizó trechos de la narrativa de su compatriota Alcides d'Orbigny (1802-1857), quien recorrió partes de América del Sur entre 1826 y 1833. Cabe observar que D’Orbigny tampoco estuvo en el río Madeira ${ }^{32}$ y que sus observaciones fueron obtenidas a través de un viajero de las monzones.

El comercio de Vila Bela se hace a través del río Madeira; para esa navegación se emplean las gariteas, grandes embarcaciones de base plana, con una capacidad de carga de 20 a 30 toneladas y cubiertas con una lona.

Esas embarcaciones parten tres o cuatro veces al año de Pará a Mato Grosso, remontan el río Amazonas, el río Madeira y el río Itenes o Guaporé hasta su destino. Esas embarcaciones podrían ser mucho más grandes, si no fuese por las caídas de agua del río Madeira, que obligan a descargarlas y arrastrarlas por tierra sobre troncos redondos, o a tirarlas vacías, con cuerdas, mientras que las mercaderías son cargadas por hombres hasta superar los obstáculos. El río Madeira alcanza una anchura de dos quilómetros y una profundidad de diecisiete metros y sería totalmente navegable por barcos a vapor si no fuese por los rápidos y las cascadas.

Las gariteas utilizan velas y remos en el río Amazonas hasta la desembocadura del río Madeira, después remontan a remo hasta la primera cascada; es ahí que comienzan las dificultades y el trabajo.

32 D’Orbigny, Descripción geográfica, t. I, pp. 239-241. 
Más allá de los rápidos y las cascadas navegan penosamente a remo hasta la confluencia con el río Itenes y el Mamoré y, desde ese punto hasta el Fuerte de Beira; ahí renuevan sus víveres para remontar hasta Vila Bela o Mato Grosso.

Esa navegación exige un año desde la partida hasta el retorno y es utilizada únicamente para mercaderías pesadas.

En el viaje de ida siembran los campos entre los rápidos o cascadas, a lo largo de la ruta, para cosechar al retorno (A. d'Orbigny). ${ }^{33}$

Esta es una síntesis bastante precisa de lo que era un viaje de monzones; el río es el camino, un vector de comunicación y comercio; se especifica el tipo de embarcación utilizado y su capacidad de carga, así como las modalidades practicadas para navegar, a vela, a remo. Se hace referencia a que esta navegación podría ser más ágil y más rentable si pudiesen utilizarse barcos de vapor, pero esto es imposible por la existencia de obstáculos naturales, lo que exige pericia y grandes esfuerzos de los viajeros. El informante da a entender que en la década de 1830 se trataba de un camino ya en desuso, utilizado únicamente para mercaderías pesadas.

Las mismas informaciones - sin la referencia al desuso- se encuentran en los diarios de los expedicionarios lusitanos, aunque escritas con otro vocabulario y muchos detalles; fueron esas las que Castelnau reprodujo en las páginas de Histoire du voyage. Pero para ilustrar su mapa optó por un lenguaje más sucinto, consciente de que los datos eran compatibles. Y para construir el dibujo del mapa se valió íntegramente del trabajo ejecutado por la caravana liderada por Ricardo Franco, como se constata en la nota colocada en la

33 Castelnau, Géographie, plancha 14. 
plancha 12, inmediatamente debajo del centro, a la izquier$\mathrm{da}$, en la que informa de las bases cartográficas utilizadas:

$1^{\circ} .20$ observaciones astronómicas hechas por la Expedición Científica que fue responsable por demarcar las fronteras de Brasil, bajo las órdenes del rey de Portugal, las que son señaladas con $\Delta$

$2^{\circ}$. La Gran Carta que ellos levantaron

$3^{\circ}$. Y, finalmente, la memoria que ellos redactaron.

Esa Comisión determinó la longitud en tres puntos, que son: la desembocadura del río Madeira en el río Amazonas, la Vila de Borba y las desembocaduras de los ríos Mamoré y Guaporé en el Madeira. ${ }^{34}$

Más explícito, imposible. Al dibujar el río Madeira, Castelnau puso en evidencia la deuda que contrajo con la "expedición científica" portuguesa que, a finales del siglo xviII, realizó las primeras observaciones astronómicas en la parte brasileña de la Amazonia. Informa literalmente que utilizó la "gran carta" que ese equipo había producido y también la "memoria", vale decir, el diario que aquellos expedicionarios habían redactado. Y como si eso no fuera suficiente, en la "Introducción" de la Géographie afirma textualmente que la carta que publica "nada más es una reducción del magnífico trabajo de la Comisión portuguesa de límites, que permanece manuscrita y de la cual nos fue dada una copia en Río de Janeiro por el gobierno brasileño, con su habitual generosidad". ${ }^{35}$

34 Castelnau, Géographie, plancha 12, énfasis en el original.

35 Castelnau, "Introductión”, en Géographie, p. v.; destaque de la autora. 
A su vez, la lectura del capítulo XXX de Histoire $d u$ voyage muestra que, de hecho, la construcción textual de la narrativa y la elaboración del mapa tuvieron como fundamento aquellos trabajos. Pero en la narrativa, el conde viajero también hace alusión a un sustancioso conjunto de fuentes escritas y cartográficas, tanto manuscritas como impresas, que tuvo a su disposición. Entre éstas, además de a la Memória del ingeniero Almeida Serra, se refiere a los diarios legados por los astrónomos que lo acompañaron, al Diário de viagem de Lacerda e Almeida, publicado en 1841, al de Silva Pontes, publicado en 1846, a la Notícia do rio Madeira, una memoria manuscrita de José Coelho de Abreu, que recibió en Belém do Pará, y también al citado escrito de Informes de Haenke.

Sin embargo, cuando revisamos esas fuentes, vemos que Castelnau las utilizó poco y que su mayor deuda es realmente con el diario de Ricardo Franco de Almeida Serra, que aún permanecía manuscrito; ese diario sólo fue impreso en $1859 .{ }^{36}$

Sí, la mayor parte de lo que escribió en el capítulo XXX de Histoire du voyage es copia de párrafos completos de ese diario, que el conde apenas tradujo al francés. Algunos fueron colocados, incluso, en cajas de texto del mapa, para describir las cascadas, el grado de peligro que representan y la manera de evitarlos, entre otros datos. Por ejemplo, al indicar en el mapa la localización de la cascada de Ribeirão - la décima del río Madeira-, comenta: “[...] esa cascada es la más peligrosa y la más difícil de pasar. Su corriente es asustadora. Está llena de piedra e islas, y se extiende por

36 Almeida Serra, “Diário do Rio Madeira”, pp. 397-432. 
8 quilómetros. Se requiere de varios días para remontarla. Ahí se descargan las canoas y la carga es llevada por tierra". ${ }^{37}$

Podemos leer la misma informacion tanto en el diario de Almeida Serra como en Histoire du voyage de Castelnau.

En cuanto al "magnífico trabajo de la Comisión portuguesa de límites, que permanece manuscrita y de la cual nos fue dada una copia en Río de Janeiro por el gobierno brasileño, con su habitual generosidad", se trata del Mappa do rio Madeira desde a sua Confluência no Amazonas até a juncção dos Rios Mamoré e Guaporé que a Real Senhora por intervenção do $I_{l} l^{m o}$ e Ex $x^{m o}$ Senhor Martinbo de Mello e Castro Ministro e Secretário d'Estado dos Negocios Ultramarinos faz de presente subir o Governador e Capitão General da Capitania de Matto Grosso e Cuiabá João de Albuquerque de Melo Pereira e Castro, de autoría de los sargentos mayores de ingenieros Ricardo Franco de Almeida Serra y Joaquim José Ferreira, que lo dibujaron en Mato Grosso en la década de 1790 y actualmente se conserva en buen estado en el acervo del Archivo Histórico del Ejército, en Río de Janeiro. ${ }^{38}$ ¡Ese es realmente un "magnífico” y gran mapa!

Realizado a tinta y acuarela, en un formato longitudinal de $65.5 \times 105.0 \mathrm{~cm}$, presenta el cuerpo fluvial del río Madeira desde su encuentro con el Mamoré hasta su desembocadura en el Amazonas, vale decir, el mismo trecho que aparece en la Carte francesa. Almeida Serra y Ferreira ejecutaron ese dibujo con extremo rigor, detallando todo el universo

37 Castelnau, Géographie, plancha 14.

38 AHE. Código 3243 AM. Debido a su gran tamaño aún no ha sido posible obtener una copia íntegra de ese mapa. 
acuático del Madeira. Lagos, islas y cascadas vienen identificados con sus nombres y localizados de acuerdo con las coordenadas geográficas. Además, los dos ilustrados hombres de la ciencia lusitana enriquecieron su mapa con decenas de notas explicativas, que indican la manera de trasponer las cascadas y los territorios indígenas, entre otros datos. Pero en el mapa de autoría de los comisarios de límites la atención recaía más sobre el territorio que, por disposición del Tratado de San Ildefonso, debía ser configurado como frontera, y no en el río como vía comercial.

El análisis de ese mapa, en comparación con el que Castelnau publicó, nos lleva a concordar con el conde: su Carte no es nada más que una reducción del Mappa do rio Madeira. Toda la base cartográfica de la Carte es deudora de las mediciones realizadas por los portugueses, todas las informaciones textuales, incluso la toponimia utilizada para dar nombre a las localidades, los ríos, las playas y las sociedades indígenas fueron tomadas del trabajo realizado por Almeida Serra y por Ferreira; en fin, todos los datos corresponden al trabajo de aquellos lusitanos. En efecto, el original portugués, además de ser más grande y más vistoso, es más rico en detalles e informaciones que fueron dejadas de lado en el dibujo francés, con el propósito de responder mejor a sus objetivos.

Pero en su Carte el viajero hizo pequeñas correcciones a partir de medidas más recientes. Esto ocurrió, por ejemplo, en la región de Mato Grosso, como indica en la "Introducción” de la Géographie:

La posición de Mato Grosso nos pareció que debía ser alterada: de hecho, la carta y la memoria [se refiere al diario] de la 
Comisión atribuyen a Vila Bela (Mato Grosso) la longitud de $317^{\circ} 42^{\prime}$ de la Isla de El Hierro o 62 $48^{\prime}$ de París. Pero de acuerdo con las observaciones calculadas por el Sr. Daussy, esta longitud es 6222' de París.

Como resultados tuvimos que someter el conjunto de ese trabajo de la Comisión a una corrección de 025' 55” y el curso del Madeira fue registrado al este de toda esa diferencia. ${ }^{39}$

Pierre Daussy (1792-1860), que Castelnau cita como autor de los cálculos, es el “ilustre geógrafo”, el “sabio académico" que lo ayudó a definir la ruta de la expedición durante la preparación del viaje y que, al final, "tuvo la bondad de encargarse por sí mismo de calcular determinaciones” de las latitudes y longitudes. ${ }^{40}$ Así pues, Daussy corrigió los datos levantados por Ricardo Franco e, igualmente, la inexactitud que había en las informaciones portuguesas con respecto a la longitud de la desembocadura del río Abunã. Esas correcciones permitieron a Castelnau actualizar las referencias que habían sido tomadas en el lugar en el siglo XviıI y así publicar la figura del río Madeira con más precisión.

A excepción de estos pequeños ajustes, las demás informaciones que Castelnau presenta en el capítulo XXX de Histoire du voyage y en las páginas de la Géographie fueron copiadas en su totalidad del material que los expedicionarios de la tercera Partida de Límites portuguesa habían levantado.

39 Castelnau, Géographie, p. v.

40 Las informaciones y citas de este parágrafo fueron tomadas de CASTELNAU, Géographie, p. v. 
Se suele afirmar que en el periodo posindependencia fueron las informaciones reunidas y publicadas por los viajeros las que enseñaron al resto del mundo, y también a los escritores e historiadores nacionales, a ver y describir los espacios americanos. A falta de modelos locales, según observó Flora Süssekind en relación con las representaciones de Brasil, "las planchas del pintor viajero no sólo representan un Brasil, sino que también enseñan a representarlo, a describirlo". ${ }^{41}$

Esto en parte es cierto, pero si tomamos como ejemplo la narrativa y los mapas publicados por la expedición francesa, vemos que tanto en relación con el paisaje fluvial-lacustre del Pantanal como para la región amazónica bañada por el río Madeira ocurrió lo contrario. En esos casos no fueron "los relatos de viajes, los estudios en ruta" los que dieron las orientaciones a los estudiosos del lugar, y sí, los relatos locales, producidos por las expediciones que el gobierno portugués mandó hacer en el interior de su colonia sudamericana a finales del siglo xviII, los que modelaron la mirada del visitante. ${ }^{42}$ No obstante, como esos materiales no habían tenido la necesaria divulgación pública, no fueron tomados en cuenta, y ocurrió exactamente lo que Castelnau irónicamente observó en su respuesta a las críticas que recibió del militar brasileño, pues "sólo los hechos publicados se tienen como adquiridos por la ciencia”. ${ }^{43}$

41 Süssekind, O Brasil não é longe daqui, p. 39.

42 Aquí se parafrasea la información de SüsseKIND, O Brasil não é longe daqui, p. 61.

43 Castelnau, Histoire du voyage, t. III, p. 18. 
Los ingenieros Ricardo Franco de Almeida Serra y Joaquim José Ferreira, y los astrónomos matemáticos Francisco José de Lacerda e Almeida y António Pires da Silva Pontes habían hecho ciencia; el resultado de los trabajos que realizaron arduamente había definido la geografía de gran parte del interior de América Meridional, y sus mapas y diarios dan testimonio de ese hecho. ¡Pero no los publicaron! Fue el trabajo "inédito" que la "habitual generosidad de las autoridades brasileñas” franqueó al visitante lo que dio a Castelnau la primacía de llevar al público aquellas importantes noticias científicas. Y aunque éste haya indicado su fuente, fue la obra del extranjero la que perduró, en ese caso, dando a conocer útiles informaciones sobre un lugar que ni siquiera había visto; sobre un objeto que describió y publicó sin conocer, pero que insidió en el cuerpo de los hechos "adquiridos por la ciencia” sobre uno de los más grandes ríos de América Meridional.

Pero no fue sólo eso. Aquel río del Pantanal, que es el río que sirve de canal de comunicación entre las grandes lagunas Gaiba y Uberaba, que Castelnau dice haber "descubierto" y que fue públicamente desmentido, lleva hoy el nombre de Pedro II, tal como propuso el viajero.

\section{SIGLAS Y REFERENCIAS}

APMT Arquivo Público de Mato Grosso. Livro de registros do Tratado de Santo Ildefonso. Cuiabá, Mato Grosso, Brasil.

AGN Archivo General de la Nación, Biblioteca Nacional de Argentina.

AHE Arquivo Histórico do Exército. Río de Janeiro, Brasil. IHGB Instituto Histórico e Geográfico Brasileiro, Brasil. 
RIHGB Revista do Instituto Histórico e Geográfico Brasileiro, Brasil.

Alden, Dauril (ed.), Colonial Roots of Modern Brazil, Berkeley, University of California Press, 1973.

Almeida, André Ferrand, "A viagem de José Gonçalvez da Fonseca e a cartografia do rio Madeira”, en Anais do Museu Paulista, 17: 2 (2009), pp. 215-235.

Almeida Serra, Ricardo Franco de, "Diário da diligencia do reconhecimento do Paraguay desde o logar do marco da boca do Jauru até abaixo do presidio de Nova Coimbra", en Revista do Instituto Histórico e Geográfico Brasileiro, xx (1857), pp. 293-329.

Amaral Lapa, José Roberto, Economia Colonial, São Paulo, Perspectiva, 1973.

Bertrand, Michel y Laurent Vidal (organizadores), À la redéconvert des Amériques. Les voyageurs européens au siècle des indépendences, Toulouse, Presses Universitaires du Mirail, 2002.

Boudreau, Claude, L'Analyse de la carte ancienne: essai méthodologique: la carte du Bas-Canada de 1831 de Joseph Bouchette, Ste-Foy, Québec, CELAT, Université Laval, 1986.

Bouza, Fernando, "Introducción”, en Fundación Carlos de AmbeRES (ed.), 1995, pp. 11-17.

Canavarros, Otávio, O poder metropolitano em Cuiabá (1727-1752), Cuiabá, EdUFMT, 2004.

Carneiro de Mendonça, Marcos (coord.), Rios Guaporé e Paraguai: primeiras fronteiras definitivas do Brasil, Río de Janeiro, Xérox do Brasil, 1985.

Castelnau, Francis de, "Relatório dirigido ao Sr. Ministro da Instrução Pública pelo Conde de Castelnau, encarregado da uma missão na América Meridional", en Jornal do Commmercio do Rio de Janeiro (10 sep. 1846). 
Castelnau, Francis de, Géographie des parties centrales de l'Amérique $d u$ Sud, et particulièrement de l'Equateur au tropique du Capricorne, París, Chez P. Bertrand, Libraire Editeur, 1854.

Castelnau, Francis de, Histoire du voyage, París, Chez P. Bertrand, Libraire Éditeur, 1850 -1851.

Castelnau, Francis de, "Notice sur l'expédition envoyée par le gouvernement français dans l'Amérique du Sud", en Bulletin de la Société de Géographie, vIII (1847), pp. 330-345.

Correa Filho, Virgílio, História de Mato Grosso, Río de Janeiro, Instituto Nacional do Livro, 1969.

Costa, Maria de Fatima, "Paisagens narrativas do espaço amazônico", en Ramos, Patriota y Pesavento (coord.), 2008, pp. 64-77.

Costa, Maria de Fatima, “A paisagem do Brasil representada por Francis de Castelnau”, en Naxara y Camilotti (coords.), 2013, pp. 71-96.

D’Orbigny, Alcides, Descripción geográfica, histórica y estadística de Bolivia, París, Librería de los Señores Gide y Compañía, 1845.

Davidson, David, "How the Brazilian West was won”, en Alden (ed.), 1973, pp. 61-106.

Fundación Carlos de Amberes (ed.), De Mercator a Blaeu. España y la Edad de Oro de la cartografía en las diecisiete provincias de los Países Bajos, Catálogo de la Exposición, Madrid, Fundación Carlos de Amberes, 1995.

Haenke, Thaddeus, "Memoria sobre los ríos navegables que fluyen al Marañon”, en Anales de la Biblioteca, I (1990), pp. 151-171.

Harley, John Brian, La nueva naturaleza de los mapas. Ensayos sobre la historia de la cartografía, traducción de Leticia García y Juan Carlos Rodríguez, México, Fondo de Cultura Económica, 2005.

Huerta, Mona, "Le Voyage aux Amériques et les revues savantes françai-

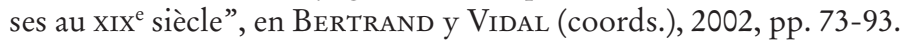


Kirchheimer, Jean-Georges, Voyageurs francophonesen en Amérique Hispanique au cours du XIXe siécle: répertoire bio-bibliographique, París, Bibliothèque Nationale de France, 1987.

Lacerda e Almeida, Francisco José, Diário de Viagem do Dr. Francisco José Lacerda e Almeida pela capitania do Pará, Rio Negro, Matto-Grosso, Cuyabá e S. Paulo, nos anos de 1780 a 1790, São Paulo, Typ. da Costa Silveira, 1841.

Moreira Freire, Zeferino Pimentel, "Confutação da existência do novo rio Pedro II, apresentado pelo Sr. Conde de Castelnau em seu Relatório", en Jornal do Commercio do Rio de Janeiro, xxi: 269 (28 sep. 1846).

Naxara, Márcia e Virgínia Camilotti (coords.), Conceitos e Linguagens. Construções identitárias, São Paulo, Intermeios, UNESP, campus Franca, 2013.

Pontes Pinto, Emanuel, Hidrovia do Grão-Pará a Mato Grosso. Projeto para integração da fronteira oeste da Amazônia Colonial entre os rios Madeira, Mamoré e Guaporé (1797-1800), Porto Velho, ABG, 1998.

Pontes, António Pires da Silva, "Diário da expedição que partiu do Quartel General de Barcelos para Vila Bela”, en Carneiro de MenDONÇA (coord.), 1985, pp. 156-185.

Ramirez, Henri, "Etnônimos e topônimos no Madeira (séculos XVIxx): um sem-número de equívocos", en Revista Brasileira de Linguística Antropológica, http://periodicos.unb.br/index.php/ling/article/ view/8838, (2010), consultado el 13 de septiembre de 2016, pp. 13-58.

Ramos, Alcides, Rosangela Patriota y Sandra Jatahy Pesavento (coords.), Imagens na História, São Paulo, HiUcitec, 2008.

Spix, Johann Baptist von y Carl Friedrich Philipp von Martius, Atlas zur Reise in Brasilien, Múnich, M. Lindauer, s/a.

SüsseKInd, Flora, O Brasil não é longe daqui: o narrador, a viagem, São Paulo, Companhia das Letras, 1990. 